\title{
LDH SÉRICA EM CÃES COM NEOPLASIAS MALIGNAS E BENIGNAS
}

(LDH serum in dogs with neoplasms benign and malignat)

\author{
Sandra Vogel Seixas ${ }^{1}$, Rosangela Locatelli Dittrich, Daniele Von Krüger, Luciane Laskoski, \\ Sheron Sierakowski, Thierry Grima de Cristo \\ 1Correspondência: sandra_vogel_seixas@yahoo.com.br
}

RESUMO: A lactato desidrogenase (LDH) é uma enzima citossólica, presente no músculo esquelético, coração, hemácias, pulmões, rim, fígado. Na medicina veterinária a LDH sérica é mensurada em pacientes com suspeita de lesões musculares. Porém, atualmente há poucos estudos verificando a sua importância no auxilio prognóstico de pacientes oncológicos. Foram analisados os resultados da LDH sérica em 40 amostras, sendo 32 com neoplasias malignas: adenocarcinoma (21), mastocitoma (7) e linfoma (4) e oito pacientes com neoplasias benignas: tumor venéreo transmissível-TVT (3), adenoma (5). Os níveis de LDH tiveram um comportamento diferenciado em cada tipo de neoplasia, demonstrando maior elevação em pacientes portadores de neoplasias malignas com metástase que foram a óbito. A LDH é indicada para auxiliar na rotina clínica de pacientes oncológicos com metástase para avaliação de prognóstico.

Palavras-chave: bioquímicos, cães; soro; LDH

ABSTRACT: Lactate dehydrogenase (LDH) is a cytosolic enzyme present in skeletal muscle, heart, blood cells, lung, kidney, liver. In veterinary medicine serum LDH is measured in patients with suspected muscle injury. However, currently there are few studies verifying its importance in prognosis aid of cancer patients. The results of serum LDH were analyzed in 40 samples, 32 with malignant neoplasms: adenocarcinoma (21), mast cell tumor (7) and lymphoma (4) and eight patients with benign neoplasms: venereal tumor transmitted-TVT (3), adenoma (5). LDH levels had a different behavior in each type of cancer, demonstrating higher elevation in patients with malignant tumors with metastasis who died. LDH is indicated to assist in routine clinical cancer patients with metastasis to prognosis assessment.

Key Words: biochemists; dogs, serum, LDH 
LDH serum in dogs with neoplasms benign and malignat

\section{INTRODUÇÃO}

A lactato desidrogenase (LDH) é uma enzima citossólica, presente no músculo esquelético, coração, hemácias, pulmões, rim, fígado (Lopes, 1998).

$\mathrm{Na}$ medicina veterinária a $\mathrm{LDH}$ sérica é mensurada em pacientes com suspeita de lesões musculares (Kamila et al., 2010).

Segundo Zanatta et al. (2003) na medicina humana a mensuração da lactato desidrogenase (LDH) sérica é utilizada como indicador de prognóstico de pacientes com linfoma não-Hodgkin, porém na medicina veterinária valores elevados de LDH foram observados em cães com leucemia e gatos com doenças linfoproliferativas.

Atualmente há poucos estudos sobre o comportamento da LDH sérica em cães com diferentes neoplasias. Segundo Marconato et al.(2009) na medicina veterinária a confirmação precoce de neoplasia nos animais é um desafio, devido a falta de marcadores tumorais adequados, sendo normalmente utilizada a biopsia como diagnóstico confirmatório.

Este estudo retrospectivo teve como objetivo avaliar os valores da LDH total sérica, mediante análises dos resultados da enzima em diferentes tipos de neoplasias malignas e benignas, comparando estes dados com a ocorrência de óbito e metástase.

\section{MATERIAL E MÉTODOS}

Foram analisados dados retrospectivos de pacientes atendidos no Hospital Veterinário da Universidade Federal do Paraná (UFPR) no ano de 2012, diagnosticados com neoplasia por de exames citopatológicos

histopatológicos e acompanhamento no setor de oncologia. Todos os cães realizaram tratamento, que incluiram: quimioterapia, cirurgia e cirurgia com quimioterapia.
As análises bioquímicas foram realizadas no Laboratório de Patologia Clínica Veterinária da Universidade Federal do Paraná. A dosagem de LDH é feita de rotina no soro de cães com neoplasia. As amostras analisadas foram de cães machos e fêmeas, com idades entre 3 a 14 anos. As amostras não apresentavam hemólise ou lipemia. Foram analisados os resultados de 40 LDH séricas sendo $32 \mathrm{com}$ neoplasias malignas: adenocarcinoma (21), mastocitoma (7) e linfoma (4) e oito pacientes com neoplasias benignas: tumor venéreo transmissível-TVT (3), adenoma (5). Os valores de LDH obtidos foram avaliados pelo teste Shapiro Wilk e posteriormente, aplicouse o teste de Kruskal Wallis entre os grupos experimentais.

\section{RESULTADOS E DISCUSSÃO}

Das oito amostras de neoplasias benignas analisadas observou-se 0 aumento da LDH em seis. Estes valores da LDH variaram entre 241,5 até 465,0 , totalizando $75 \%$ das amostras com elevação na LDH. Sendo que $80 \%$ correspondiam a Adenoma e $66 \%$ a TVT. Todos os pacientes com neoplasias benignas não foram a óbito.

Para as neoplasias benignas os valores da LDH não ultrapassaram o dobro do limite superior do valor de referência. Os valores de referência utilizados da LDH (U/L) 45,0 - 233,0 são do Laboratório de Patologia Clínica Veterinária da Universidade Federal do Paraná.

Nos pacientes com neoplasias malignas, foram mensuradas 32 amostras das quais 24 apresentaram a LDH aumentada com valor que variava entre 240,0 a 2000 , totalizando $75 \%$ das amostras com elevação do LDH. Nestas incluem-se $100 \%$ dos Linfomas, $76 \%$ dos Adenocarcinomas e $57 \%$ dos Mastocitomas.

Em cães com neoplasias malignas 0 aumento da LDH teve resultados que 
ultrapassaram o dobro do limite superior do valor de referência.

Todos os pacientes que foram a óbito apresentavam metástase. O aumento da LDH nestes pacientes ultrapassou o limite superior do valor de referência, sendo que em um paciente com linfoma a LDH ultrapassou oito vezes o limite superior do valor de referência. Esses resultados são semelhantes aos descritos por Zanatta et al.(2003) que relatam no momento do diagnóstico, o tempo de sobrevida é maior em cães com os níveis de LDH mais baixos no soro.

Analisando todos os resultados da LDH estatisticamente, não foram observadas diferenças significativas entre pacientes com neoplasia malignas quando comparados a pacientes com neoplasias benignas. Esses resultados são semelhantes aos citados por Azenha et al. (2011) que relatam não haver diferença significativa entre os valores de LDH em neoplasias malignas e benignas.

$\mathrm{Na}$ análise da LDH em neoplasias malignas, verificou-se que seu aumento mais significativo foi no linfoma, seguido pelo adenocarcinoma e mastocitoma. Esses resultados encontrados são semelhantes aos descritos por Marconato et al.(2009), que observaram que o linfoma foi a principal neoplasia com maior aumento. A atividade da LDH sofre alterações devido à severidade da neoplasia, grau de lesão tecidual, metástase, protocolo terapêutico utilizado e resposta do paciente ao tratamento. Campos et al. (2012) relatam que os níveis de LDH estão relacionados ao estadiamento e a evolução da doença, indicando um pior prognóstico quando sua concentração sanguínea está elevada.

Os valores de LDH obtidos foram avaliados pelo teste Shapiro Wilk. Posteriormente, aplicou-se o teste de Kruskal Wallis entre os grupos experimentais. Todas as análises consideraram $p<0,05$.

Os animais que desenvolveram metástase tumoral ou que foram a óbito evidenciaram valores de LDH superiores (Tabela 1). Os dados dos animais de cada grupo experimental estão demonstrados nas figuras 1 e 2 .

Tabela 1- Medianas e amplitudes interquartis obtidas entre os grupos experimentais. Letras diferentes representam diferença significativa pelo teste de Kruskal Wallis $(p<0,05)$.

\begin{tabular}{lcc} 
Medianas e amplitudes inter-quartis \\
Grupo & 538,15 & $\mathrm{~A}$ \\
Metástase & $(371-1541,1)$ & \\
Grupo sem & 288,5 & $\mathrm{~B}$ \\
Metástase & $(206,5-358,5)$ & \\
\hline
\end{tabular}

Figura 1 - Gráfico de dispersão de valores de $\mathrm{LDH}$ por animal do grupo metástase, com seis animais.

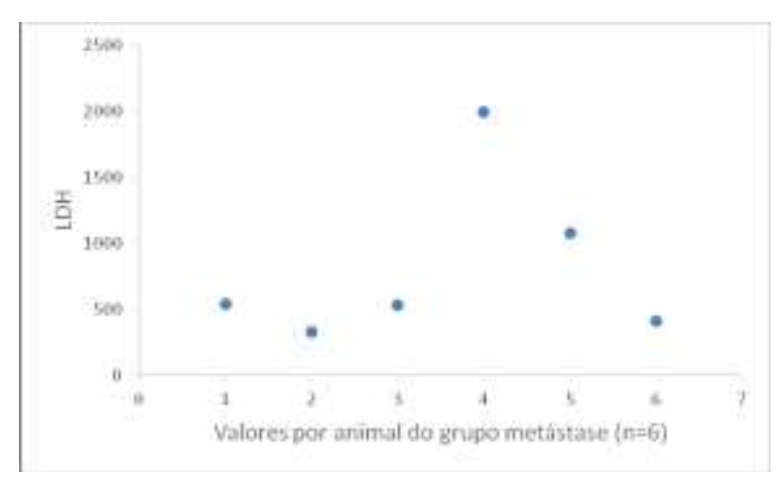

Figura 2 - Gráfico de dispersão de valores de $\mathrm{LDH}$ por animal do grupo sem metástase, com 34 animais.

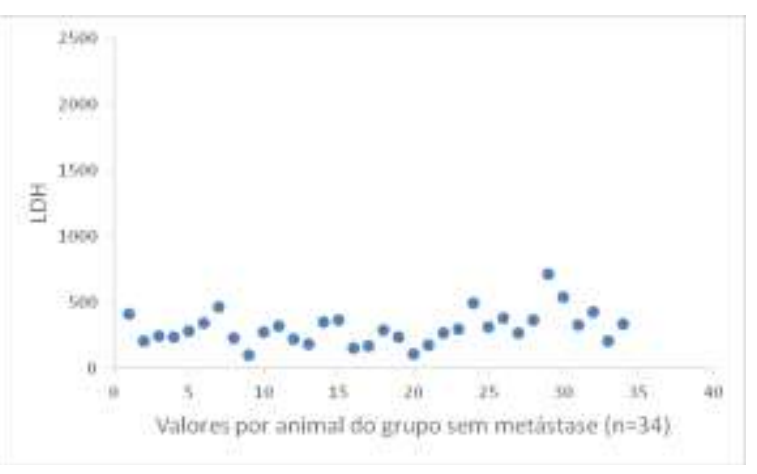




\section{CONCLUSÃO}

A LDH é uma enzima, útil na avaliação dos pacientes portadores de neoplasia, principalmente com metástase. Quanto maior os níveis da enzima menor a sobrevida do paciente. Portanto a LDH é indicada para auxiliar na rotina clínica de pacientes oncológicos com metástase para avaliação de prognóstico. Os níveis de LDH tiveram um comportamento diferenciado em cada tipo de neoplasia, demonstrando maior elevação em pacientes portadores de neoplasias malignas com metástase.

\section{REFERÊNCIAS}

AZENHA, E.S; SOBREIRA, M.F.R; CASALE, R.V.P; et al. Atividade de lactato desidrogenase como fator prognóstico de neoplasia em cães.São Paulo;2011.

CAMPOS.L,C; LAVALLE, G.E; ESTRELA-LIMA, A; et al. CA15.3, CEA, and LDH in Dogs with Malignant Mammary Tumors. Journal of Veterinary Internal Medicine 12;26:1383-1388.

GLANNOULAKI, E.E.; KALPAXIS, D.L.; TENTAS, C.; et al. Lactate dehydrogenase Isoenzyme pattern in sear of patientes with malignant diseases. Clinical Chemistry, v.35, n.3, p. 396-399, 1989.

CORREA, K. S; MATTOSO, C. R, S; SILVA, C.F,G,T; LAGOS,M. S; TAKAHIRA,R. K; LOPES, R.S; Enzimas musculares e eletrólitos em equinos submetidos a esforço físico prolongado, suplementado com acetato de Tocoferol e Selênio. Veterinária e Zootecnia. 2010 março.; 7(1):85-93.

LOPES,J.J. Enzimas no laboratório Clínico - Aplicações Diagnósticas (Analisa Diagnóstica Ltda). Belo Horizonte , 1998.
MARCONATO,L.

CRISPINO,G.; FINOTELLO, R.; et al. Serum lactate dehydrogenase activity in canine malignancies - Veterinary and Comparative oncology, p.236-243, 2009.

ZANATTA, R. ABATE, O; D' ANGELO,A; et al. Diagnostic and Prognostic Value of Serum Lactate Dehydrogenase (LDH) and LDH Isoenzymes in Canine Lymphoma. Veterinary Research Communications,27 Suppl.1 (2003) 449452. 